\title{
Histopathological Profile of Pediatric Solid Malignant Neoplasm in Tertiary Care Centre
}

\author{
Syeda Ayesha and Bharat R Sonwane* \\ Department of Pathology, Government Medical College \& Hospital Aurangabad -431003, Maharashtra, India.
}

\begin{abstract}
Background: There is rise in incidence of pediatric tumors all over the globe. In developing country like India childhood morbidity \& mortality is mainly due to malnutrition \& infections but there is significant rise in incidence of pediatric neoplasm which is now becoming a distinct \& important entity to be dealt upon.

Objectives: To study the incidence of solid pediatric malignant neoplasms, the age and sex distribution in cases of solid pediatric malignant neoplasms and various histopathological appearance and patterns of solid pediatric malignant neoplasms.

Methods: An observational study of solid pediatric malignant neoplasms in childhood was done over a period of 2 years, from November 2016 to October 2018 in the age group of 0-14 years. The institutional ethical committee Government Medical College \& Hospital, Aurangabad- Maharashtra India has given approval for this study.

Result: Total 180 cases of solid pediatric neoplasm were studied. The total sample received during study period was 180 out of which 55 were malignant. Out of 55 malignant tumors 30 were observed among males and 25 were observed among females. Most of the malignant tumors were observed among 11-14 yrs age group, followed by those observed among 0-3 years.

Conclusion: It can be concluded from our study that common solid malignancies in pediatric age group excluding hemato-lymphoid malignancies include nephroblastoma, retinoblastoma, neoplasms of gonads \& bone tumors. Male predominance is a salient feature of childhood tumors. Most common solid tumors of childhood originate from embryonal tissue and tumors of epithelial origin are rare. A larger pediatric population based study would provide us with greater insight details about solid pediatric neoplasms.
\end{abstract}

Keywords: Solid pediatric neoplasm, Nephroblastoma, Bone tumors, Retinoblastoma.

\section{Introduction}

There is rise in incidence of pediatric tumors all over the globe. Though malignant neoplasm are rare in children \& accounts for small fraction as compared to overall global tumor burden they are second only to accidental deaths in developed world accounting for $10-12.3 \%$ of total deaths. ${ }^{[1]}$ In developing country like India childhood morbidity \& mortality is mainly due to malnutrition \& infections but there is significant rise in incidence of pediatric neoplasm which is now becoming a distinct \& important entity to be dealt upon. ${ }^{[2]}$

Childhood neoplasm exhibit unique features like they arise from embryonal cells are rapidly responsive to treatment. Survival rates in these patients have improved dramatically due to advancement in diagnostic modalities \& aggressive combined management. ${ }^{[2]}$ Common malignancies in pediatric age group include leukemia (30\%), CNS tumors (20\%), lymphomas (12\%) followed by neuroblastoma, retinoblastoma, soft tissue tumors, renal neoplasms, bone tumors \& neoplasms of gonads. ${ }^{[3]}$

Male predominance is salient feature of many childhood tumors, genetic difference in immune function may be responsible for increased incidence of lymphoid tumors. ${ }^{[4]}$ The patterns of prevalence of pediatric malignancies have considerable similarities, but there are certain differences which highlights the need of regional epidemiological studies.

Moreover, the pathological subtypes \& presentation of different cancers vary from one region to another. ${ }^{[5]}$ The appropriate management of pediatric tumors will require detailed clinical history, tumor site, size and precise histopathological diagnosis, accurate grading \& staging systems wherever possible along with other relevant clinical investigations. Histological type \& subtype is important for understanding etiology and progression of disease. [6]

\section{Materials and Methods}

An observational study of solid pediatric malignant neoplasms in childhood was done over a period of 2 years, from November 2016 to October 2018. All the cases which were referred to our hospital were included in this study. The age group of the patients was 0-14 years. The material consisted of the entire surgical pathology specimens of pediatric patients received in the Department of Pathology 
from surgery department. All the solid malignant neoplasms among children below 14 years of age were considered. The institutional ethical committee Government Medical College \& Hospital, Aurangabad- Maharashtra India has given approval for this study.

\section{Result}

The total sample received during study period was 180 , out of which 55 were malignant. Hence the percentage of solid malignancy was $30.55 \%(n=55)$. Out of 55 malignant tumors 30 were observed among males and 25 were observed among females with male to female ratio of
$1.2: 1(n=55)$. Most of the malignant tumors were observed among 11-14 yrs age group, followed by those observed among 0-3 years, 4-7 years and 8-10 years respectively. $(n=55)$

Bar diagram (Fig. 5) shows the incidence of various malignant tumors observed in the study. During the study, Wilms tumor was observed most commonly (15), followed by retinoblastoma (12), Osteosarcoma (7), Ewing's tumor (6), germ cell tumor of ovary (6), central nervous system tumor (3) and two cases each of Hepatoblastoma, nasopharyngeal carcinoma and Rhabdomyosarcoma.

Table 1: Age Distribution of Malignant Tumors.

\begin{tabular}{|l|l|l|l|l|}
\hline AGE GROUP & $0-3$ YRS & $4-7$ YRS & $8-10$ YRS & $11-14$ YRS \\
\hline No. of patients & 19 & 11 & 03 & 22 \\
\hline Percentage (\%) & $34.54 \%$ & $20 \%$ & $5.45 \%$ & $40 \%$ \\
\hline
\end{tabular}

Table 2: Sex ratio in various studies.

\begin{tabular}{|l|l|l|l|l|}
\hline Sr. No. & Studies & Male & Female & Ratio M:F \\
\hline 1. & Gite Vandana $^{[8]} 2015$ & 24 & 11 & $2.2: 1$ \\
\hline 2. & CT Nagaraja] $^{[9]} 2015$ & 40 & 26 & $1.53: 1$ \\
\hline 3. & Banerjee $^{[11]}$ et al 1986 & 432 & 173 & $2.5: 1$ \\
\hline 4. & Das S $^{[12]]} 1994$ & 127 & 65 & $1.95: 1$ \\
\hline 5. & Yeole BB B $^{[13]} 2001$ & 814 & 516 & $1.58: 1$ \\
\hline 6. & Monga T $^{[14]} 2017$ & 30 & 30 & $1: 1$ \\
\hline 7. & Present study & 30 & 25 & $1.2: 1$ \\
\hline
\end{tabular}

Table 3: Incidences of Various Malignancies Observed By Various Workers.

\begin{tabular}{|c|c|c|c|c|c|c|c|}
\hline Sr. No. & $\begin{array}{l}\text { Type of } \\
\text { malignancy }\end{array}$ & $\begin{array}{l}\text { Sharma S } \\
2004^{[7]}\end{array}$ & $\begin{array}{l}\text { Harsh Mohan } \\
2014^{[8]}\end{array}$ & $\begin{array}{l}\text { CT Nagaraja } \\
2015^{[9]}\end{array}$ & $\begin{array}{l}\text { G Vandana } \\
2015^{[6]}\end{array}$ & $\begin{array}{l}\text { Gupta N } \\
2017^{[10]}\end{array}$ & $\begin{array}{l}\text { Present } \\
\text { study }\end{array}$ \\
\hline 1 & Leukemia & -- & -- & -- & -- & -- & -- \\
\hline 2 & CNS malignancy & -- & 23.64 & 7.57 & -- & 8.33 & 5.45 \\
\hline 3 & Retinoblastoma & 6.4 & 6.36 & 3.03 & 8.57 & 3.33 & 21.81 \\
\hline 4 & Lymphoma & 21.4 & 7.27 & 31.81 & -- & 38.33 & -- \\
\hline 5 & Kidney tumors & 19.4 & -- & 9.09 & 25.71 & 8.33 & 27 \\
\hline 6 & Neuroblastoma & 3.8 & 0.91 & 3.03 & 11.42 & 3.33 & -- \\
\hline 7 & $\begin{array}{l}\text { Soft tissue } \\
\text { sarcoma }\end{array}$ & 10.3 & 17.27 & 19.69 & -- & 8.33 & 3.63 \\
\hline 8 & Hepatoblastoma & 0.6 & -- & - & 2.86 & -- & 3.63 \\
\hline 9 & Bone tumors & 9.7 & 32.73 & 12.12 & -- & 15 & 23.62 \\
\hline 10 & Carcinoma & 11 & 7.27 & -- & 5.71 & 3.32 & 3.63 \\
\hline 11 & Germ cell tumor & 8.4 & 3.64 & 13.63 & 8.57 & 11.66 & 10.90 \\
\hline 12 & Miscellaneous & 8.4 & -- & -- & 31.43 & 3.32 & 3.63 \\
\hline
\end{tabular}




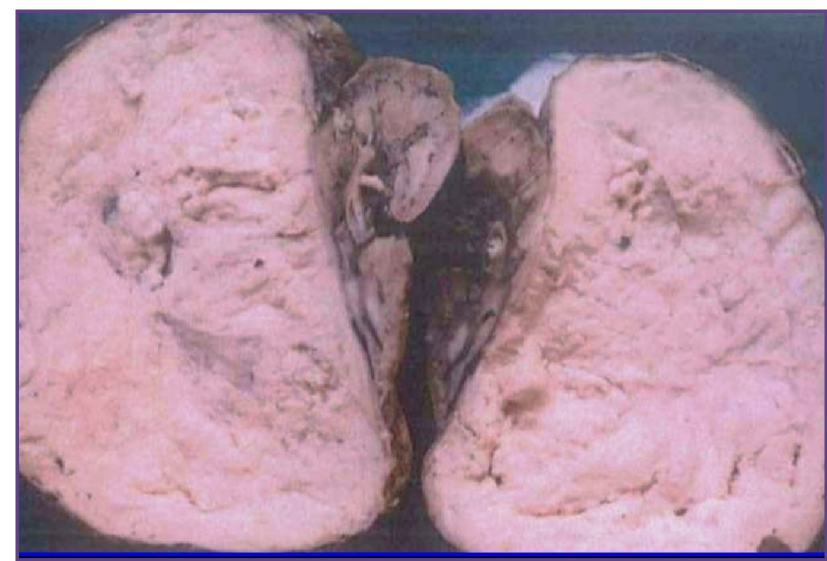

Fig. 1: Gross specimen of Wilms tumor (Nephroblastoma) showing characteristic tan to gray color and wellcircumscribed margins.

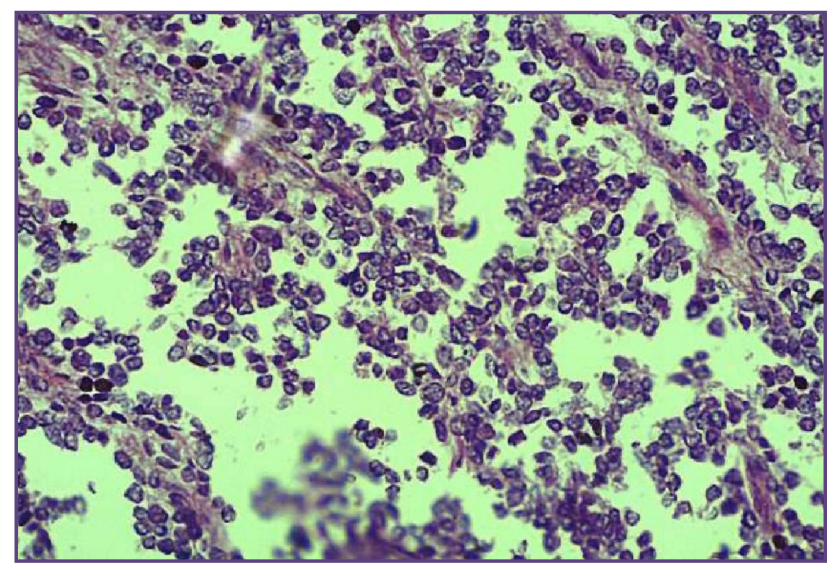

Fig. 3: Microscopy of Ewing sarcoma shows fairly uniform small cells with round, dark blue nuclei and poorly defined cytoplasm (40x).

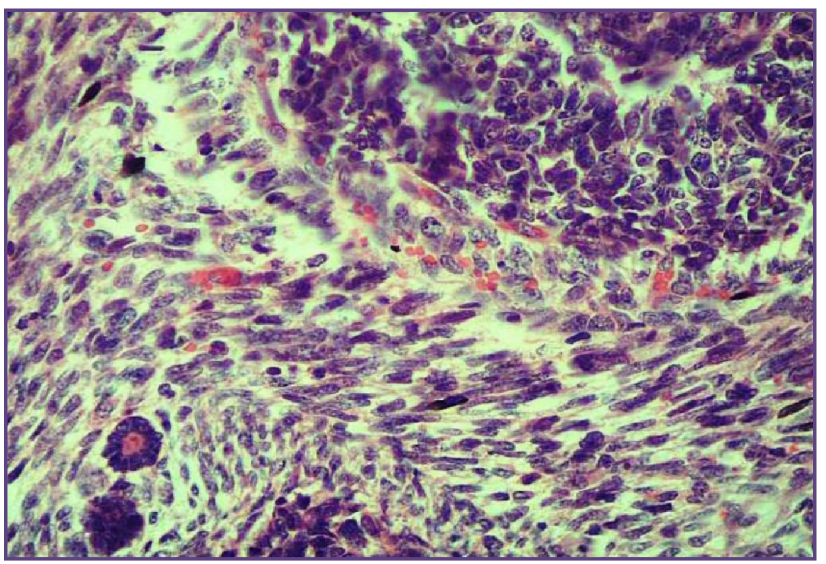

Fig. 2: Microscopy of Wilms tumor (Nephroblastoma) with tightly packed blue cells consistent with the blastemal component and interspersed primitive tubules, representing the epithelial component (40x).

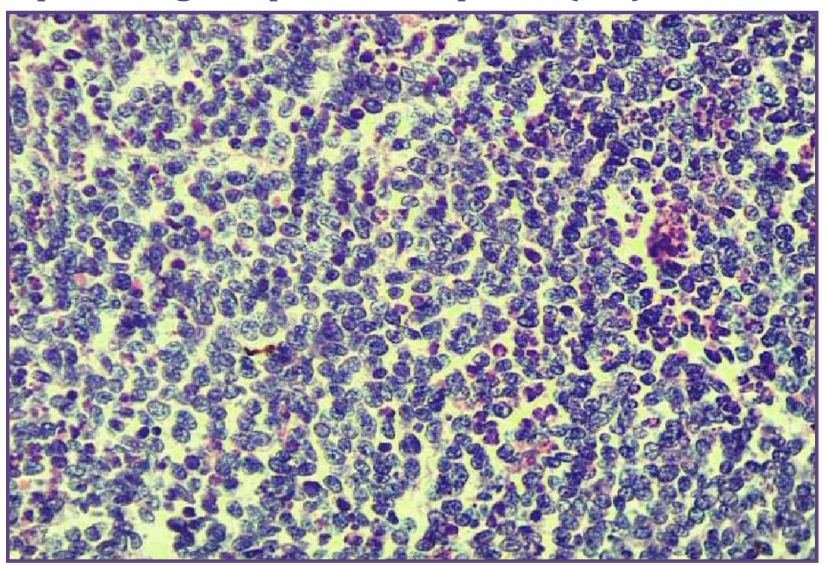

Fig. 4: Microscopy of Retinoblastoma shows densely packed, round neoplastic cells with hyperchromatic nuclei, scant cytoplasm and abundant mitoses are randomly distributed (40x).

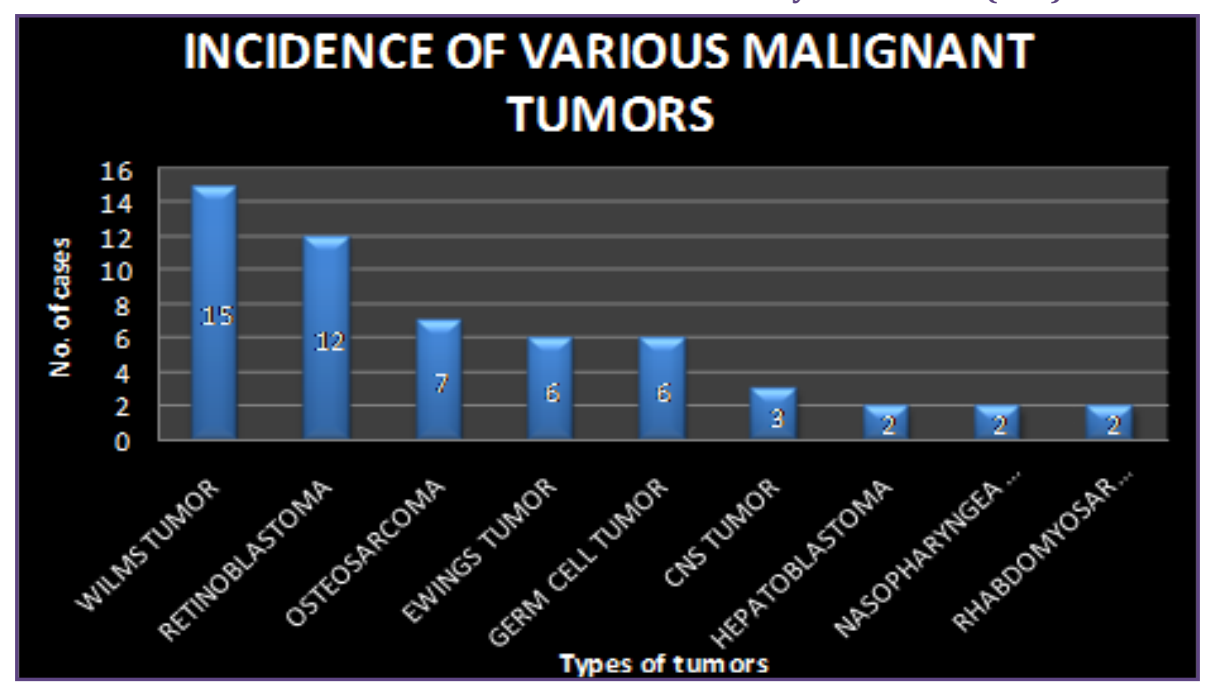

Fig. 5: Bar diagram shows the incidence of various malignant tumors observed in the study. 


\section{Discussion}

The present study was undertaken to analyse the histopathological spectrum of solid pediatric malignant neoplasms in age group of 0-14 years. We have studied 55 cases of solid pediatric malignant neoplasms.

Total samples of benign as well as malignant lesions received in histopathology section from pediatric patients during the study period were 180 . Out of 180 number of malignant tumors observed were 55 i.e. $30.55 \%$. Sharma $\mathrm{S}$ in 2004 reported a total of 472 cases out of which $32.62 \%$ were malignant. Harsh Mohan et al in 2014 studied 385 cases out of which 110 cases i.e. $28.57 \%$ were malignant. The incidence of nephroblastoma, retinoblastoma $\&$ bone tumors was found to be much higher than in other studies but was comparable with that found in study by S. Sharma 2004, Harsh Mohan et al 2014 and CT Nagaraja et al in 2015. [7] [8] [9] The most common group affected was 1114 years $(40 \%)$ followed by $0-3$ years $(34.54 \%), 4-7$ years $(20 \%)$ and $8-10$ years $(5.45 \%)$. Similarly in study by CT Nagaraja et al $2015,40 \%$ of tumors were observed in age group of $10-15$ years, followed by $32 \%$ in $5-10$ years \& $28 \%$ in $0-5$ years. ${ }^{[9]}$ In study by Harsh Mohan et al in 2017 $58 \%$ cases were observed in $11-14$ years $27 \%$ in $5-9$ years and $15 \%$ in $0-5$ years. ${ }^{[8]}$ In study by Gupta $\mathrm{N}$ et al in 2017 , $40 \%$ cases were observed in $11-15$ years, $31.66 \%$ in $6-10$ years and $28.33 \%$ in $0-5$ years. ${ }^{[10]}$ In study by Monga $\mathrm{T}$ et al in 2017 maximum number of pediatric tumors was seen in age group of $11-14$ years $41.66 \%$. $^{[14]}$

Sex incidence in the present study we found male preponderance with male: female ratio of 1.2:1 for solid malignant pediatric neoplasms. This ratio is in accordance with sex ratio obtained by various authors as shown in table -2

Distribution of various malignancies: In the present study, most common malignancies observed below 5 years of age were mainly embryonal tumors i.e. nephroblastoma, retinoblastoma, hepatoblastoma. In the present study nephroblastoma constitute about $27.27 \%$ of all tumors followed by bone tumors $23.62 \%$, retinoblastoma $21.81 \%$. More or less these findings were comparable with that observed by other authors. The incidence of nephroblastoma \& retinoblastoma in the present study was found to be higher than that found by other workers as shown in table- 3; but this finding co-relates with incidence of nephroblastoma observed by G Vandana et al $\&$ incidence of retinoblastoma found by Das $S$ et al. ${ }^{[6][12]}$ In study by Nnadi $\mathrm{G}$ et al in 2016 commonest malignancy observed was nephroblastoma $29.63 \%$. ${ }^{[15]}$ In a study by Shrushti M et al in 2019 total 18 malignant tumors were studied most of which werev small round cell tumors followed by intra abdominal tumors comprising of renal and adrenal tumors. ${ }^{[16]}$

Bone tumors including osteosarcoma \& Ewing's sarcoma and germ cell tumors were found above 10 years of age. Nephroblastoma: 15 cases of nephroblastoma were observed during the study period constituting about $27.27 \%$ of all malignancies. The mean age of presentation was 3.2 years. Female preponderance was observed in present study with female to male ratio of $2.7: 1$. On microscopy 13 out of 15 cases showed classic triphasic nephroblastoma composed of epithelial, blastemal \& stromal elements with favorable histology. One case was biphasic type. One case of teratoid Wilms tumor was reported having typical triphasic pattern along with chondroid differentiation. Retinoblastoma: Retinoblastoma constitutes about $21.81 \%$ of all neoplasms in the present study. The average age of presentation was 3 years. Male preponderance was observed in the present study with male to female ratio as $2: 1$.In the present study, none of the patients had bilateral retinoblastoma. On microscopy, all these cases showed well differentiated retinoblastoma and optic nerve was not involved in any of the cases. Bone tumors: The incidence of bone tumors in present study is $23.62 \%$. All the 13 patients were above 10 years of age and male to female ratio was $6: 1$. The ratio of osteosarcoma to Ewing's sarcoma in present study is 1.16:1. Osteosarcoma: In present study osteosarcoma was observed in 7 patients with $\mathrm{M}$ : F ratio of $6: 1$ with mean age at presentation of 13.28 years. Most of the cases occurred around knee joint. Ewing's sarcoma: 6 case of Ewing's sarcoma were observed in present study with male to female ratio of 5:1 with average age of 12.5 years. Central nervous system malignancy: Total 3 cases of CNS malignancy were observed in the present study constituting about $5.45 \%$ of total malignancy. This lower incidence in our study is as the neurology and neurosurgery department in our institution is in initial stages of development and all the 3 cases were referred to our department for review. The mean age of presentation was 10.33 years. In present study all the 3 patients were male. In the present study all three tumors were infratentorial in location, occurring in cerebellum. Out of these 3 cases two were cerebellar astrocytoma and one was cerebellar medulloblastoma. Both the cases of astrocytoma were of diffuse astrocytoma variant and medulloblastoma was of large cell variant. Malignant germ cell tumor: Total 6 cases of malignant germ cell tumor were observed during present study constituting $10.90 \%$ of all malignancies. All the cases were observed in female patients with site of lesion in all cases being ovary. All the cases were observed in age group of 10-14 years with mean age of 12.5 years. In the present study we observed 3 cases of dysgerminoma, 2 cases of mixed germ cell tumor and 1 case of embryonal carcinoma. 
Rhabdomyosarcoma: Total 2 cases of rhabdomyosarcoma occurred during the study period constituting 3.63\% of total malignancies. Both the patients studied were below 12 years of age with male to female ratio of 1:1. The average age at presentation was 6 years. Hepatoblastoma: Two cases of hepatoblastoma were observed constituting $3.63 \%$ of all malignancies. Male to female ratio was 1:1 with average age of presentation as 3 years. Nasopharyngeal carcinoma: Total 2 cases of nasopharyngeal carcinoma were observed during present study constituting $3.63 \%$ of all malignancies. The two cases in present study were of 10 year and 11 year old male presented with nasopharyngeal mass. On microscopy undifferentiated type of nasopharyngeal carcinoma was seen.

\section{Conclusion}

It can be concluded from our study that common solid malignancies in pediatric age group excluding hematolymphoid malignancies include nephroblastoma, retinoblastoma, neoplasms of gonads \& bone tumors. Male predominance is a salient feature of childhood tumors. Most common solid tumors of childhood originate from embryonal tissue and tumors of epithelial origin are rare. A larger pediatric population based study would provide us with greater insight details about solid pediatric neoplasms.

\section{Acknowledgements}

I am grateful to the Dean, Government Medical College \& Hospital, and Aurangabad Maharashtra for allowing me to conduct this study.

\section{Funding}

Nil

\section{Competing Interests}

Nil

\section{Reference}

1. Bhalodia JN, Patel MM. Profile of pediatric malignancy: A three year study. National journal of community medicine. 2011; 2(1).

2. Shah Sh1, Pervez S, Hassan Sh: Frequency of malignant solid tumours in children; J Pak Med Assoc. 2000 Mar; 50(3):86-8.

3. Vinod K P (ed), Arvind B (ed), O P Ghai: Ghai Textbook of essential pediatrics, 8th edition, CBS Publishers 2013, pg 599.
4. Bryan E. H, Kenneth F, Barbara N, Meenakshi S: Pediatric Solid Malignant Neoplasms : A comparative analysis;; Indian Journal of Pathology \& Microbiology-54(3), 2011.

5. Knutti R E- Maliganat tumors of Childhood : California Medicine J 1952 Jan;76(1) :27.

6. Vandana G, Maruti D. The Spectrum of Malignant Solid Childhood Tumors in the age group of 0-12 years. Paediatr Neonatal Nurs Open J. 2015;2(3):85-90.

7. Sharma S, Mishra K, Agarwal S, Khanna G. Solid tumors of childhood. The Indian Journal of Pediatrics. 2004 Jun 1;71(6):501-4.

8. Raipal S P, Imeet M, Reetu K, Geetanjali J, Isha D \& Harsh M-Spectrum of Non Hematological Pediatric Tumours: A clinico pathological study of 385 cases; Indian J Med Pediatric Oncol 2014 apr-june; 35(2): 170-174

9. Chandrashekhar T. N, Ravindra B. P, Geetalakshmi U, Ramesh B K- Solid Malignant Tumors of Infancy and Childhood: A Histopathological Study- Scholars Journal of Applied Medical Sciences, 2015;3(1C) 8b:167-174.

10. Gupta N, Choudhary M, Pachar S, Prakash Dhaka J, Verma R. Solid malignant pediatric tumors: a histopathological study. International Journal of Contemporary Pediatrics. 2017 Mar; 4(2):442.

11. Banerjee CK, Walia BN, Pathak IC. Pattern of neoplasms in children. The Indian Journal of Pediatrics. 1986 Jan 1;53(1):93-7.

12. Das S, Chakraborty AK, Mukherjee K, Kundu BK, Haldar KK. Profile of malignant lesions amongst children in North Bengal. Indian pediatrics. 1994 Oct;31:1281.

13. Yeole BB, Advani SH, Sunny L. Epidemiological features of childhood cancers in greater Mumbai. Indian pediatrics. 2001 Nov 1;38:1270-7.

14. Monga T, Kuka AS, Singh N. Histopathological Profile of Solid Tumours of Childhood and Infancy in Northwest Punjab, India. Indian Journal of Pathology and Oncology. 2017 Apr; 4(2):166-73.

15. Nnadi G.I, Egejuru R.O, Uchendu O. J. Childhood malignant tumours in owerri; a histopathological review. Int. J of Forensic Med Invest 2017; 2(2)19-24.

16. Srushti M, Balachandra B, Krutika S. Andola, Sainath K. A. Clinical, cytological and histopathological spectrum of pediatric lesions with emphasis on pediatric tumors. IP Archives of Cytology and Histopathology Research 2019; $4(3): 265-276$.

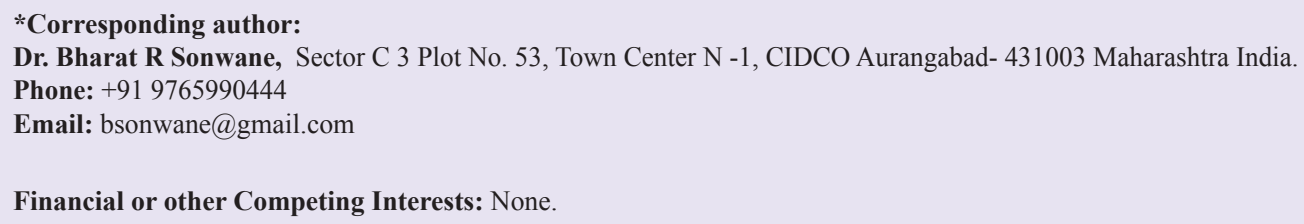

